\title{
Global warming "heating up" the ICU through Candida auris infections: the climate changes theory
}

\author{
Giovanni Misseri, Mariachiara Ippolito and Andrea Cortegiani* (B)
}

The simultaneous and independent worldwide outbreaks of Candida auris invasive infections seem to be a puzzling paradox $[1,2]$. Since its first isolation, $C$. auris has risen several questions on how it could have appeared, survived, and thrived [1]. Several speculative hypotheses have been proposed. Although misuse of antimicrobials and over-abuse of azoles have been considered the main contributors to $C$. auris emergence [2,3], these do not completely justify its spreading.

One of the most recent theories considers changes in climate conditions as a causative factor altering infectious disease ecology [4, 5] (Fig. 1). Humans and microbes had been influencing each other for decades. Global warming is one of the major components of climate change connected to human activities, having considerable impact on health and indirectly boosting infectious diseases. Only few fungal species can be considered as pathogenetic for humans, as the majority of mammals are remarkably resistant to invasive fungal diseases. Besides immunological responses, humans are characterized by a "thermal restriction zone" that protects against infections. Human-induced climate changes may be responsible for the progressive narrowing of this thermal restriction zone, defined as the difference between human basal temperature and environmental temperature. As C. auris is more thermotolerant if com- pared to other yeasts, global warming might have played an important role in its emergence [4]. Although the specific ecological niche has not been identified yet, the climatic oscillations effect on wetlands might have contributed to enrich this potential habitat, conferring thermal and salinity tolerance to $C$. auris non-pathogenetic naïve strains. Acquisition of virulence factors might be explained considering the potential transfer of virulence genes from other pathogenetic Candida spp. to $C$. auris naïve strains, or by the combination of global warming and UV radiations that might have induced genetic mutations. The upgrade of $C$. auris strains, from saprophyte to pathogenetic yeasts, has witnessed an intermediate avian host, thus permitting its transmission to humans. Overtime, genetic and epigenetic changes have led to an extreme adaptability of $C$. auris to different ecological niches, leading to the development of persistent outbreaks in healthcare settings $[4,5]$.

Although global warming seems to be an appealing theory, it is not possible to ignore other factors which might explain $C$. auris rise. High population densities, poor hygiene, migrations, international travels, and pollution might indeed have contributed to the persistence of $C$. auris and acquisition of antifungal resistance [4]. Future studies are needed to identify its evolutionary reservoirs and validate the climate changes theory.

\footnotetext{
* Correspondence: andrea.cortegiani@unipa.it

Department of Surgical, Oncological and Oral Science (Di.Chir.On.S.). Section

of Anesthesia, Analgesia, Intensive Care and Emergency. Policlinico Paolo

Giaccone, University of Palermo, Via del vespro 129, 90127 Palermo, Italy
}

(c) The Author(s). 2019 Open Access This article is distributed under the terms of the Creative Commons Attribution 4.0 International License (http://creativecommons.org/licenses/by/4.0/), which permits unrestricted use, distribution, and

reproduction in any medium, provided you give appropriate credit to the original author(s) and the source, provide a link to the Creative Commons license, and indicate if changes were made. The Creative Commons Public Domain Dedication waiver (http://creativecommons.org/publicdomain/zero/1.0/) applies to the data made available in this article, unless otherwise stated. 


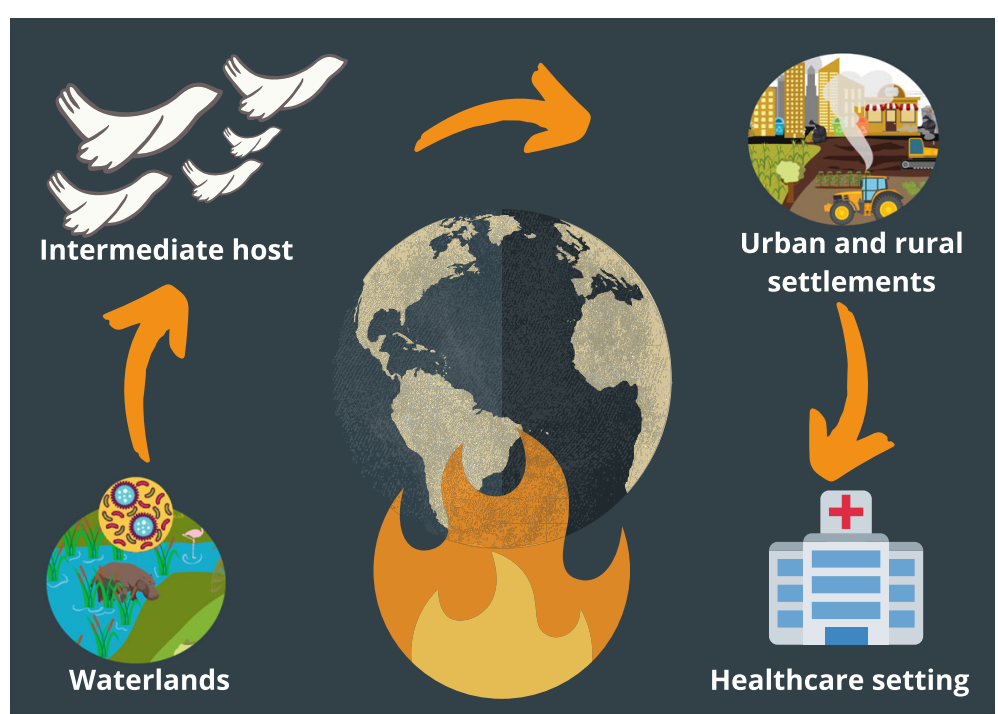

Fig. 1 Global warming and the climate changes theory for C. auris emergence and spread. Rising ambient temperatures (caused by human activities) might have selected thermotolerant yeasts in wetlands; subsequently, acquiring opportunistic traits, C. auris might have spread through different ecosystems (wetlands, rural, and urban areas) thanks to intermediate avian hosts; following development of resistance and resilience through interspecies transmission, C. auris invades healthcare settings, leading to persistent outbreaks and causing infections in susceptible critically ill patients

\section{Abbreviation}

ICU: Intensive care unit

\section{Acknowledgements}

None.

\section{Authors' contribution}

$\mathrm{GM}, \mathrm{MI}$, and $\mathrm{AC}$ conceived the content, wrote the manuscript, and approved the last version.

\section{Funding}

None.

\section{Availability of data and materials}

Not applicable.

\section{Ethics approval and consent to participate}

Not applicable.

\section{Consent for publication}

Not applicable.

\section{Competing interests}

$\mathrm{GM}$ and $\mathrm{Ml}$ declare to have no competing interests. $\mathrm{AC}$ is member of the Advisory Board of Critical Care.

Received: 19 November 2019 Accepted: 12 December 2019

Published online: 19 December 2019

\section{References}

1. Cortegiani A, Misseri G, Fasciana T, Giammanco A, Giarratano A, Chowdhary A. Epidemiology, clinical characteristics, resistance, and treatment of infections by Candida auris. J Intensive Care. 2018;6:69. https://doi.org/10. 1186/s40560-018-0342-4

2. Cortegiani A, Misseri G, Chowdhary A. What's new on emerging resistant Candida species. Intensive Care Med. 2018. https://doi.org/10.1007/s00134 018-5363-x.
3. Cortegiani A, Misseri G, Giarratano A, Bassetti M, Eyre D. The global challenge of Candida auris in the intensive care unit. Crit Care. 2019;23:150. https://doi.org/10.1186/s13054-019-2449-y.

4. Casadevall A, Kontoyiannis DP, Robert V. On the emergence of Candida auris: climate change, azoles, swamps, and birds. mBio 10:e01397-19. 2019. https://doi.org/10.1128/ mBio.01397-19.

5. Jackson BR, Chow N, Forsberg K, Litvintseva AP, et al. On the origins of a species: what might explain the rise of Candida auris? J Fungi. 2019;5:58. https://doi.org/10.3390/jof5030058.

\section{Publisher's Note}

Springer Nature remains neutral with regard to jurisdictional claims in published maps and institutional affiliations. 